\title{
Critical Success Factors In Implementing ITIL in the Ministry of Education in Saudi Arabia: An Exploratory Study
}

\author{
Abdullah S Alqahtani \\ School of Information and Communication Technology, \\ Griffith University, Gold Coast, Australia \\ Faculty of Computing, Umma Al-Qura University, \\ Alqunfudah, Saudi Arabia
}

\begin{abstract}
This paper engages with the ITIL framework for IT service delivery within the specific context of the Ministry of Education in the Kingdom of Saudi Arabia (KSA). A literature review process is used to develop a critical success factors (CSFs) for the implementation of the ITIL framework in an organisation, based on a series of models like TAM and UTAUT, and then put into an overall conceptual model of use behaviour towards ITIL described by [1]. The conceptual model is then deployed in the field through a series of interviews with IT professionals within the Ministry of Education in the KSA. The interviews are semi-structured, and were intended to draw out the corresponding factors for success and the factors that have hindered the implementation of ITIL within this organisation. The data confirm the view of the literature that strong leadership and management involvement is essential both as a success factor in its own right, and as the means by which other success factors are enabled. The findings of paper make two observations. First, the literature sets out a series of quite precise success factors that relate to project management, communication, and quality control. The data presented in this research project demonstrate that in practice it is hard to make clear all of these factors to such a level of detail within the Ministry of Education in Saudi. Second, the implementation of ITIL is more reflexive than the literature and the conceptual model would initially demonstrate.
\end{abstract}

Keywords-Information Technology Infrastructure Technology (ITIL); Information Technology Service Management (ITSM); Ministry of Education (MoE); the Kingdom of Saudi Arabia (KSA)

\section{INTRODUCTION}

The purpose of this paper is to analyse the factors that affect ITIL implementation in the KSA, specifically in the Ministry of Education, and to enable identification of variables influencing its implementation. Reference [2] analysed the Information Technology Infrastructure Library (ITIL) and found that it is an appropriate framework for best practice, which guides IT Service Management (ITSM) and suggested numerous advantages to an organisation such as it mitigates risk, reduces cost, and improves quality. However, ITSM provides a platform for the construction of IT operations, enabling organisations to deliver quality IT services meeting business requirements and other obligations such as service-level agreements (SLAs). Which is a written agreement documenting the required levels of service.
As we know that education is the most important parts in any country and specially emerging countries like Saudi Arabia. Therefore, the MoE in KSA implemented ITIL and IT managers and experts may be faced with some problems such as meeting customer requirements, poor understanding of dealing with the new operation, poor communication with other departments requesting the operation's execution, the culture of work on the new operations whether that of the employees or the heads of departments in general. Lack of maintenance of new specialist skills for properly implementing this new technology. Thus the aim of this research is to find out and explore what happen there. However, there is no research that has been investigated the implementation of ITIL in MoE.

The aim of this study is to explore concept of critical success factors (CSFs) influencing the implementation of an ITIL framework. Focusing on the Ministry of Education, and adopts an exploration approach. However, the current study takes a different direction which is optimisation of e-services systems in the KSA's Ministry of Education, and variables associated with effective implementation and management of ITIL. Lack of extensive information on the implementation of ITIL in the KSA generally, and the Ministry of Education in particular, has contributed to the decision to carry out this study. The research achieves these aims through answering the following research questions:

RQ1: How is the Ministry of Education implementing ITIL in the KSA?

RQ2: What are some of the crucial factors for successful implementation of ITIL in the Ministry of Education in the $K S A$ ?

The research contributes to increase the body of ITIL implementation knowledge in new context which is e-services in Saudi Arabia. The results of paper will enable IT managers and experts in the MoE in Saudi Arabia to better implement, understand, evaluate, and explore success factors of ITIL for their work. The paper includes useful information of ITIL implementation that helps executive management, academics and other organisations to understand ITIL process. This paper framework adopted the concept of CSFs of ITIL which are applied to study the linkage between CSFs and the UTAUT 
model proposed by [1] to measure users' behaviour impacts toward the use of ITIL implementation. The paradigm of the research employs a qualitative approach through the use of semi-structured interview instruments that were administered over Skype and recorded.

This study employs the thematic analysis technique in order to analyse the data that has been collected from the recorded interviews. The technique also is premised on research and describes the process of identification of data, the coding of the data, creating and discovering themes, the reviewing and the naming of the themes, and the writing of the report.

\section{LITERATURE REVIEW}

\section{A. Implementation of ITSM}

Reference [3] defined ITSM is a framework for delivery of IT that concentrates on the management field of IT processes such IT services and products. The benefits expected from implementing an ITIL framework such as ITSM are: "alignment with business needs, negotiated achievable service levels, predictable consistent processes, efficiency in service delivery, measurable, improvable services and processes, alignment of IT services with current and probable future business needs, improved quality of IT services, a reduction in the long-term costs of service provision, better communication between suppliers and customers, and a common language where terms are defined" $[2,4-6]$. The benefits of ITSM can be different based on the objective of the system and administrative aims. Hence, one should determine the aims of IT and a business to obtain a high level of effectiveness and understanding of the organisational needs, directors, and stakeholders who are affected by an organisation's behaviour and policies. The requirements of business apply through the investment of IT made by IT management or stakeholders. These requirements include customer satisfaction by providing IT services to them, improved quality, quick response to customers' needs, and evaluation of service delivery, specifically.

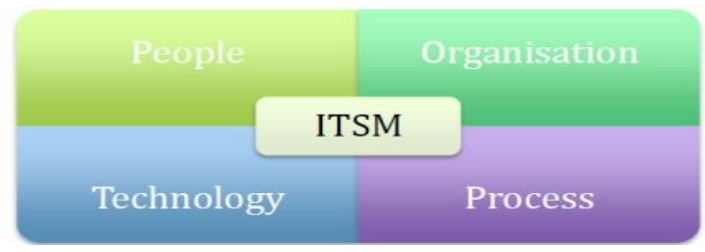

Fig. 1. The components of ITSM (Source: [3])

\section{B. Implementation of ITIL}

According to [7] "The concept of ITIL emerged in 1972 when IBM undertook research into the quality of services delivery in order to release its Information System Management Architecture (ISMA). In the 1980s, the first version of ITIL was released by a British public body called the Central Computer and Telecommunication Agency, now known as the UK Office of Government Commerce, with the aim of improving the quality of IT services and best practices observed in the industry. ITIL v2 was released between 2000 and 2002; in that time, Microsoft used it as a foundation from which to develop its operation framework."
The year 2011 saw the publication of ITIL v3. Figure 2 shows the five phases of this were: "Service Strategy," "Service Design," "Service Transition,", and "Continual Service Implementation." The advantage of this new version has been said to be that it "provides a framework for IT governance and proscribed best practice in IT service management" [8].

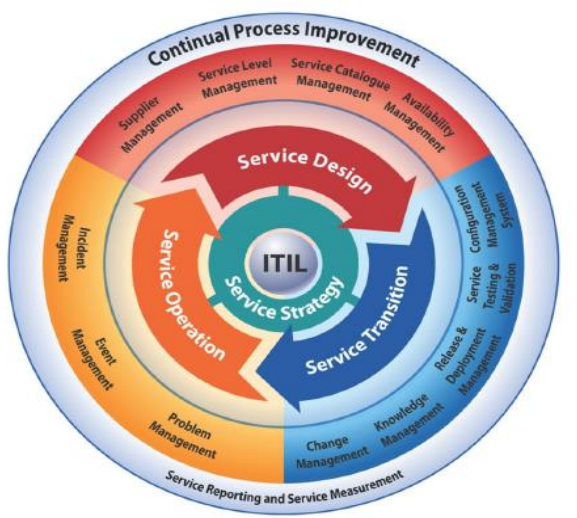

Fig. 2. Service life cycle phases of ITIL (Sources: [7-9])

"Service strategy" Service strategy provides the guidance that enables an organisation to define business strategy and is supported by IT strategy effectively through some key activities such as defining the market.

"Service design" According to [8], this "provides guidance for the planning and architecting services that fall within a business's strategy."

"Service transition" Reference [8] explain that this "provides the guidance for the improvement of capacities, to transfer new and changed services into operations" through recognising the service requirements in service design to be effective and achieved in a service operation, and to control failure risks and disruptions.

"Service operation" Service operation manages the services currently utilised by a business, focuses on the practices in service management, and ensures that the delivery of services to the customer by the service provider are achieved effectively.

"Control service improvement" Control service improvement (CSI) is something that helps guide how people can identify possible areas for improvement across all service lifecycle stages by measuring and improving efficiency, effectiveness, service levels, technology, and processes used in the whole of services management.

\section{Previous Research of ITIL implementation}

\section{1) ITSM Based on the ITIL}

Reference [9] conducted a systematic review of previous research studies related to ITSM and ITIL implementation. They discussed the implementation from two perspectives: strategies and methods, and implementation status. The authors adopted the categorisation structure of [10]. They used the primary categories of empirical and conceptual approaches. They identified 37 studies. Of these, 21 were published in academic journals, and another 16 were in the 
form of publications of the proceedings of conferences. Empirical views were captured by means of the use of experiments, case studies, interviews, and multi-method research. Conceptual research was used in order to find relevant studies. The authors used 11 articles based on research in Australia, seven articles based on research in North America, and 17 articles based on research in Europe.

Nine articles discussed the implementation status of ITSM and ITIL based on surveys conducted to address implementation on a broad scale in the US, Brazil, and Europe. This research demonstrated surveys of participant companies from nine articles in 2009. The findings were that $45 \%$ of participating corporations were using ITIL, and that $15 \%$ were planning for implementation in the US. In Brazil, $21 \%$ of the firms were using ITIL and $51 \%$ planned to use ITIL. In Europe, $20 \%$ of companies in developed countries were using ITSM, and only $8 \%$ of companies in transition countries were using ITSM. Furthermore, the research presented CSFs, which include drivers and barriers identified in previous studies for effective implementation of ITSM. Using the Delphi method, this research found that five articles mentioned CSFs. Reference [11] indicated that success factors that influence the implementation of ITIL and ITSM include senior management involvement, communication with employees and stakeholders, and different cultures. In addition, this research found that previous studies focused on top management support as a main factor in the success of projects. However, training of employees, broad organisational participation in process design and providing resources, and readiness to change are all factors in the successful implementation of ITIL and ITSM. Another key finding of the research was that significant outcomes or benefits of both ITIL and ISM included better customer satisfaction and better quality of service $[4,5,12]$.

Despite the previous studies that focused on the implementation status of three different levels of analysis worldwide, this research did not explore success factors in developing countries by focusing on the importance of IT functions such as process management and ensuring the implementation or planning of ITIL in enterprises. Further, it did not focus on the organisational level in terms of evaluating the overall implementation status in an organisation and the process level by checking each ITIL process to be implemented in an organisation.

\section{2) ITIL CSFS}

Reference [13] discussed CSFs for the implementation of ITIL by using the analytical hierarchy process (AHP) as a systematic approach to improving solutions for the decision problem. The research mentioned that most previous studies have examined ITIL in organisations by using multiple case studies in their projects [2, 5, 11, 14]. Hence, this study applied qualitative analysis to identify CSFs that affect ITIL implementation. The research method used surveys and interviews of 15 experts from a financial company in the
United Arab Emirates due to their knowledge about best practices implementation through compliant strategies with other enterprises skilled in IT service management. Data analysis was based on all participants' opinions on this research, and such participants included the IT team, the end users, and top-level managers. The findings were arrived at by using the AHP model to calculate and compare the experts' priorities for each of the existing criteria and then by combining them into groups based on survey results. Table 1 presents the survey results based on the criterion and ranking of participants' priorities. As can be seen in Table 1, the study indicated that IT staff and top-level managers agreed that top management support is a significant factor for the success of ITIL implementation through correct project management [9, 15]. However, the end users considered communication and cooperation to be essential factors for top management to achieve by delivering ITIL to employees and asking them for feedback during the process. However, while this research has illustrated critical factors for ITIL implementation as a systematic approach, the focus on organisational culture was scant and the researchers needed to do more exploration to ascertain the benefits delivered after the implementation of ITIL.

3) Concepts that Influence the Successful Implementation of ITIL

Reference [4] discussed CSFs that influence successful implementation of ITSM with concentration on ITIL organisations in Iran as a developing country. The factors that might affect the implementation of ITSM in organisations include: staff training, top management, communication between departments, usage of consultants and experts, careful selection of software, organisational culture, and customer satisfaction. In addition, processes are essential success factors of ITSM and managers should consider that appropriate techniques and tools should be applied [5, 12].

Reference [4] defined ITSM as a framework for constructing IT operations that enable organisations to "deliver quality IT services" and "to meet business needs" and obligation to SLAs. However, ITIL offers a complete framework of best practices for ITSM, and ITIL has been becoming more common due to the pressure to reduce costs, to push service management into excellence, to introduce SLAs to measure user experience, and because of IT's requirement to conform with regulations [5, 12]. References [4] and [16] identified several challenges that might face an organisation when establishing an ITIL framework. These include resistance of cultural change by staff, resource management problems such as employees, time, and money, and delays in the selection of the right tools.

Reference [4] used a mixed method of research by using a survey and semi-structured interviews and previous studies, and identified 22 success factors to investigate in ITIL implementation. 
TABle I. Survey Result based in the Criterion ANd RANking of Participants’ Priorities (Source: [13])

\begin{tabular}{l|l|c|c|c}
\hline \multicolumn{1}{c|}{ Criterion } & \multicolumn{2}{c}{ Ranking } \\
\hline \multicolumn{2}{c|}{} & IT Staffs & Management & Users \\
\hline F1 & Top management support & 1 & 1 & 4 \\
\hline F2 & Change management and organizational culture & 7 & 4 & 3 \\
\hline F3 & Monitoring and evaluation & 6 & 6 & 7 \\
\hline F4 & Communication and cooperation & 4 & 3 & 1 \\
\hline F5 & Project management and governance & 5 & 2 & 6 \\
\hline F6 & $\begin{array}{l}\text { Training and competence of involved } \\
\text { stakeholder in ITIL project }\end{array}$ & 2 & 5 & 2 \\
\hline F7 & $\begin{array}{l}\text { ITIL process implementation and applied } \\
\text { technology }\end{array}$ & 3 & 7 & 5 \\
\hline
\end{tabular}

In addition, they used a qualitative approach to get responses from experts through interviewing 13 project managers who were implementing ITIL; 112 questionnaires were used for the analysis.

They also conducted data analysis by applying a robust exploratory factor analysis (EFA) model, which is a measurement scale for analysis of the classic factors that help a researcher choose from many options and to minimise the number of observed variables to fewer factors in order to promote interpretation and reveal hidden structures in the data [17]. The findings classified the concepts based on extracted factors using robust EFA into five groups: "organisational, human resources, project management, managerial, and processes." These concepts affect the success of ITIL implementation. Table 2 shows the extracted components of ITIL and their associated factors.

TABLE II. COMPONENTS OF ITIL AND THEIR ASSOCIATED FACtors (SOURCE:[4])

\begin{tabular}{|c|c|c|c|}
\hline Component ID & Component Name & Factor ID & Factor Name \\
\hline \multirow[t]{4}{*}{$\mathrm{C} 1$} & Organizational & OR01 & Change-friendly culture \\
\hline & & OR02 & Project governance \\
\hline & & OR03 & Achieving agreement among different stakeholders \\
\hline & & OR04 & IT and business alignment \\
\hline \multirow[t]{3}{*}{$\mathrm{C} 2$} & Human Resources & HR01 & Staff awareness \\
\hline & & HR02 & Staff training \\
\hline & & HR03 & Involving employees in the project \\
\hline \multirow[t]{5}{*}{$\mathrm{C} 3$} & Project Management & PM01 & Proper vendors \\
\hline & & PM02 & Proper consultants \\
\hline & & PM03 & Good relationships with project consultant \\
\hline & & PM04 & Proper project management \\
\hline & & PM05 & Good project team \\
\hline \multirow[t]{3}{*}{$\mathrm{C} 4$} & Managerial & MG01 & Top management support \\
\hline & & MG02 & Management belief in project outcomes \\
\hline & & MG03 & Optimized budget allocation \\
\hline \multirow[t]{5}{*}{ C5 } & Processes & PR01 & Continuous performance assessment \\
\hline & & PR02 & Continuous monitoring and evaluation of processes \\
\hline & & PR03 & Process as a priority \\
\hline & & PR04 & Customer focused metrics \\
\hline & & PR05 & An integrated process and service based approach \\
\hline
\end{tabular}


Despite this research contributing to investigating the CSFs in the implementation of ITIL in Iranian organisations, there are some factors which need in-depth information and more exploration, such as management, processes, structure, human resources, and technology: these factors may affect ITSM. Therefore, this research cannot lead to generalisations in developing countries based on its content.

\section{ITIL IN SAUDI ARABIA}

Historically, the reception of IT in the Gulf Cooperation Council (GCC) was poor, but the current focus is embracement of the technology. In the GCC, the KSA has the highest gross domestic product (GDP) of $\$ 653$ billion in 2015 and GDP per capita is estimated at $\$ 20,813$ [18]. The importance of ICT is well understood, and the government continues to finance and support programs and policies for government transactions and services in an electronic manner. The investment in ICT will continue to increase to reflect the demand for information and communication requirements. In addition, numerous organisations continue to adopt ITIL practices such as ITSM solutions in supporting ITIL practices. For example, the Ministry of Defence, the Ministry of Finance, and the Ministry of Education in the KSA continuously invest in and adopt ITIL practices. In the Ministry of Education, the IT department and associated network are dependent on outsourcing service contracts, meaning ITIL is important in the accomplishment of strategic requirements. Network quality and operational efficiencies have continued to improve in the KSA after the standardisation of the Managed Services Unified Platform (MSUP).

\section{THEORIES}

In this paper, the framework adopted the concept of CSFs of ITIL which are applied to study the linkage between CSFs and the UTAUT model proposed by [1] to measure users' behaviour impacts toward the use of ITIL implementation. The conceptual framework is the use of ITIL in different contexts and areas previously discussed within the contexts of the Unified Theory of Acceptance and Use of Technology (UTAUT) variables, ITIL critical success factors, and the Technology Acceptance Model (TAM).

\section{A. Conceptual Framework of Use Behaviour Towards ITIL}

Reference [19] defined ITIL model, and the current study employs this framework that shows in figure 3. To accomplish the study requirements, the conceptual framework in relation with CSFs is discussed, and the focus of the study is a linkage between UTAUT variables and ITIL CSFs founding in figure 3 [1]. Furthermore, the applied technology factor and ITIL implementation are eliminated because these can be seen together as a component of the project management. The proposed conceptual framework disregards the moderators of UTAUT as proposed by [20]. The moderators disregarded "include voluntariness of use, experience, age, and gender." Reference [1] also disregarded these moderators in developing their version of UTAUT. The proposed model contains attitude, which enables measurement of behavioural intention about the requirements of the study. It is premised on the understanding that behavioural intention plays a crucial role viewed from the original TAM. Reference [20] have addressed attitude but have not included these variables in the model because it is directly linked with other cognitions. The proposed model for the current study is the reintroduction of attitude toward using measures in behavioural intention. Figure 3 summarises the proposed model for the conceptual framework of use behaviour towards ITIL.

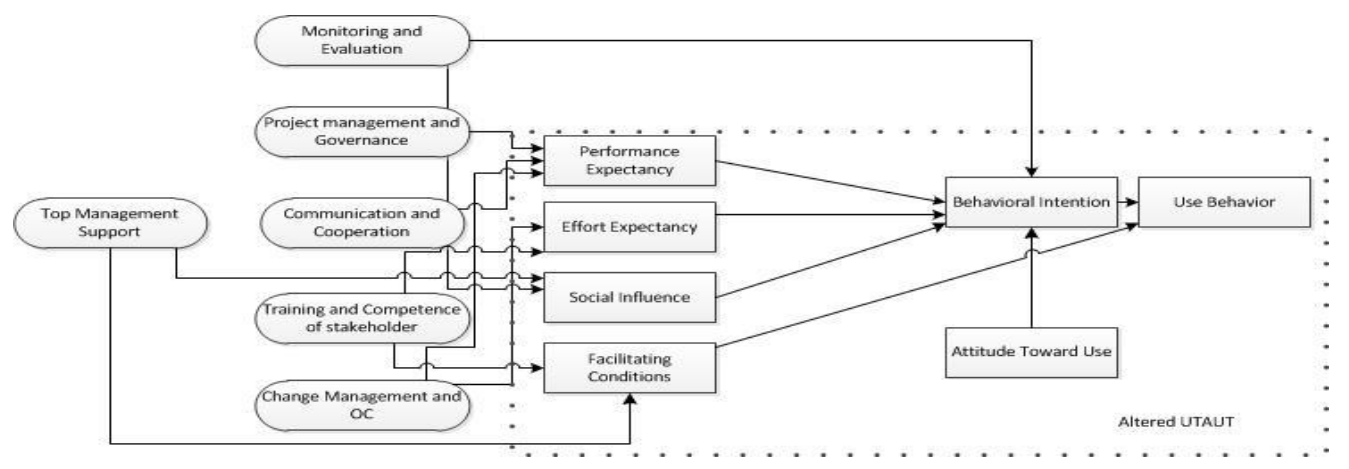

Fig. 3. Proposed model for the conceptual framework of use behaviour towards ITIL (Source: [1])

\section{RESEARCH METHODOLOGY}

\section{A. Qualitative Methods}

The appropriateness of the qualitative approach is promised on the description of phenomena approach dependent on the case study data. In addition to the qualitative approach, a case study methodology is utilised with the help of semi-structured interviews to identify ITIL implementation factors in the Ministry of Education in the KSA. Reference
[21] defined a case study as "an empirical inquiry" enabling investigation of "a phenomenon within its real-life context" and in depth, particularly in situations whereby the "boundaries" between context and phenomenon are not clear. In the implementation of ITIL in the Ministry of Education, the case study provides and obtains crucial data that relates to users' experiences. Hence, a case study is a preferred approach because of the nature of the study and the sources of the data. 


\section{B. The Research Paradigm (Epistemology)}

Reference [22] stated that epistemology is the quality of knowledge study and the determination of appropriate methods for acquisition of knowledge. For the purposes of the current study, the approach taken is the interpretivist philosophy, which is explored later on. The reason for adopting this strategy is to analyse the assimilation of human knowledge and behaviour in the ITIL implementation context in the KSA's Ministry of Education. The ultimate expectation is learning the best ITIL knowledge and practices as a determinant in understanding the current IT managers' framework.

\section{The Philosophy of Interpretivism}

Numerous authors such as [23] and [22] stated that interpretivism targets the recognition of social phenomena through studying the behaviours of individuals and groups who are tasked with a specific activity. In the implementation of e-services ITIL, many employees and managers are involved. These individuals have different perspectives and perceptions of ITIL, and the appropriate strategy to gain knowledge on ITIL implementation is to understand and learn these different perceptions. The study involves the collection of information from four participants who are IT managers and certified in ITIL.

\section{Unit of Analysis and Sampling}

In accomplishing the requirements of the study and the nature and circumstances of the KSA, a researcher is required to examine massive amounts of data. The data sampling was included four participants of the MoE in the final analysis. Reference [24] further the analysis of interviews through highlighting interview methods including linking elements, recording, and interview venue, and the introduction and conclusion of the interviews

The aim of the interviews is to collect information on the perceptions of certified ITIL experts and IT managers about the component of CSFs in the implementation of ITIL. The appropriate strategy for collecting the data is asking openended questions through Skype regarding the experiences of the respondents in ITIL projects.

\section{E. Participants}

In this paper four participants were involved, where the participants were required to complete semi-structured interviews: the interviews were carried out for around 30 minutes via Skype since the Skype application enables recording of online information. In determining the participants, the research submitted a request to the head of the Information Technology Department with the aim of identification of individuals involved in the ITIL project and individuals tasked with coordinating and operating e-services system. . The researcher obtained five names at the beginning from the MoE and, emails all of them and got four respondents and, after analysis, the researcher chose four respondents because they agreed to participate in the current research. These participants played an important role in the ITIL project in the Ministry of Education. The positions of these four respondents include Architectural Engineer, Program Manager, Computer Engineer, and Incident Manager.
The positions were targeted because of the experiences and exposure of these individuals in ITIL project and ITIL implementation compared to other individuals within the departments or the organisation.

\section{F. Data Analysis (Thematic Analysis)}

The current study utilised the inductive approach to analyse the data, the specific transactions, people, and circumstances, to gain an understanding of the relationship between different meanings and contexts [25]. It is important to remember the purpose of the study, which is the identification of the concept of CSFs influencing ITIL practices and ITIL implementation in the Ministry of Education in the KSA. In analysing the data, a thematic analysis approach was also employed. The implementation of the thematic analysis involves numerous stages, and the stages include:

- Transcribing the collected data: This stage must be accomplished without consideration of the research tool and data collection methods. The significant component is understanding the collected data and creating ideas, which contribute to the facilitation of coding. The researcher used Skype application to record online information.

- Producing early codes: From the collected data, it is imperative to produce early codes. Early codes are used in instances where important content is acquired because of easiness of identification of the nature of the content. For the purposes of this study, the manual approach has employed. After each interview, numerous codes have been identified, such as top management support and monitoring and evaluation.

- Exploring themes: The researcher explores the possible themes from the previously analysed data from the previous stage. The themes relate to the early coding and sometimes have to be combined to create themes having stronger links. The same strategy is employed in the current study, and the themes were grouped into a table to appreciate themes, such as leadership, project management abilities and aligning with customer/EndUser.

- Reviewing themes: This phase is integral after the data are grouped into appropriate themes. The stage requires rereading the themes created and determining whether the developed themes have appropriate data. For example, the concept of top management support releated to leadership theme.

- Describing and labeling themes: Reference [26] explain that this step involves defining and refining the themes through assigning each theme to the correct research phenomenon. For instance, the particpant A noted that "The Manager of the Department of Application Development is a specialist of ITIL, and he is the one who supported the decision to apply ITIL, together with a number of ITIL specialists."

- Writing the report: It is the last stage of the thematic analysis. The results are analysed, and conclusions are 
drawn. Reference [27] mentioned that the data analysis should be deep and the results should be supported with clear arguments.

\section{G. Reliability and Validity in Qualitative Research}

Reliability indicates to reproduce the same findings if the study were repeated [28]. Reference [28] suggest that validity is the interpretation of the accurate findings which reflects understanding of phenomena. However, selection of interviewees carefully is significant due to the validity of interviews that is identified by the extent to which participants are interesting to offer knowledgeable data [29]. Since strategies such as randomisation were not applicable to the current study, the researcher employed different strategies including semi-structured interview questions, data-driven coding, and accurate transcriptions to enhance the accuracy of the information and ensuring that the findings represent reality [30]. The sample sizes of participants were also considered to reflect the study requirements and purpose of this study. The validity of the current study was achieved through obtaining appropriate answers and information of four participants for the research questions that reflect ITIL implementation factors in the MoE in Saudi. Also, the current study ensured that data collection and using of thematic analysis were adopted accurately by using Skype application to record online information [31].

\section{The CASE StUdy ANALYsis}

\section{A. Identification of Themes}

The conceptual model of the CSFs [1], which can broadly be put into four stages: top management support, project management and oversight, expectations and conditions, and finally attitudinal responses. The first critical element of the model that shows in table 3 would be the support of senior leadership; something indicated by all the respondents. There would appear to be a very clear sense of direction and involvement from the senior management involved; this was not referenced in great volume in the transcripts, but it was one of the CSFs from the conceptual model that was referred to with comfortably the most clarity in the transcripts. The largest percentage of the respondents' feedback was devoted to stage two of the model, which relates to project management, training, change management, and the quality control of the system. Each of these elements was referenced by the respondents, but there was some difficulty in clarity the different CSFs among the responses. One element that was particularly evident was that it is hard, on the basis of the data, to make clear between the ideas of quality control, project management, and change management. Each of the respondents had a slightly different idea about what each of these stages constituted, and how they should be labelled. It was clear that they were referring to the same sorts of practices, in terms of planning and monitoring, but the way that the ideas of project management and change management were merged together were quite complex; there is a need for a degree of clarity over how the systems fit together into a coherent whole $[32,33]$. However, this issue with confusion between these different CSFs brought forward a much more interesting point in terms of analysing the way the model might work, in that there was considerable evidence that the implementation of ITIL is much more reflexive than the structuring of the model currently accounts for. However it is termed, there is a quality control mechanism operating within ITIL that allows for the service ultimately delivered to the end user to be the best it can be at the time; the respondents indicated that either change management teams or other people charged with quality control would check the quality of the work before it was returned to the end user, and send it back for further refinement if the requirements had not been met, which resonates with the literature to an extent [34-36]. In the conceptual model, this issue of reflexivity is hidden because the type of project management, change management, and quality control appears to be happening in parallel rather than reflexively. That is not to say that the model is ignorant of this kind of reflexivity in design, just that it does not describe what is happening in the correct dynamic sequence.

A final point of analysis from the four themes emerging from the results that presented in table 3 is that the attitudinal element of the model is similarly difficult to engage with on the basis of this data. None of the respondents really addressed this in direct terms, but instead mentioned it in passing while referring to other issues; notably with regard to change management and training. The change management issue was presented as an issue in preparation for the implementation of ITIL, in that there was identifiable 'resistance to change'; though what form this resistance took was not specified, as other literatures have $[37,38]$. This was then extrapolated into an analysis that training is the route to preventing or at least overcoming this resistance to change. In some ways, this is an unsatisfactory element of the results, in that it is not possible to further differentiate out this issue into the specific of the concept CSFs indicated in the conceptual model that presented in figure 3, and hard to relate to literature [39]. Despite this, the issues with resistance to change and the general attitudinal response to the implementation of ITIL did not seem to diminish its efficacy, and in the sense that there does seem to be something of a departure from the literature [19].

\section{FINDINGS AND DISCUSSION}

RQ1: How is the Ministry of Education implementing ITIL in the KSA?

The research data suggest that there are several important cultures that underpin the way that the Ministry of Education is implementing ITIL in the KSA. The key point is that the Ministry of Education is really driving the process. The literature review that generated the conceptual model indicated that the attitudinal aspects of the organisations involved would play a major role in whether ITIL implementation would be a success [19]; many institutions had reported that they were unsatisfied in regards to the fact that ITIL was not meeting their expectations. One of the reasons assumed for that was because of key people not accepting the implementation of ITIL as shows in table 4, therefore damaging the effectiveness of the whole $[2,38,40]$.

A number of methods for overcoming this were suggested in the literature, principally that there had to be a very clear commitment from senior management to making ITIL work, and to providing training or support to help improve attitudes toward its implementation. The remarkable thing about the 
data in this report was that, despite one or two references being made to people being unwilling to accept change, there seemed to be relatively few instances of attitudinal problems [38]; that there was clear senior management involvement seemed to be almost assumed, none of the respondents focused on it, but it was very clear, see table 4. Therefore, it seems that the Ministry of Education has been driving ITIL forward in a very clear way, as the literature would suggest [2, $5,41]$.

TABLE III. CONCEPT OF CSFS, THEMES AND ANALYSIS INTERVIEWS DISCOVERED FROM CASE STUDY

\begin{tabular}{|c|c|c|}
\hline Concept of CSFs & Themes & The case study Analysis \\
\hline Top Management Support & Leadership & $\begin{array}{l}\text { "The Manager of the Department of Application Development is a specialist of ITIL, and he is the } \\
\text { one who supported the decision to apply ITIL, together with a number of ITIL specialists." } \\
\text { "The upper management's support is the first factor for a successful implementation of ITIL. This } \\
\text { is reflected in maintaining the current technology and developing the operations whenever the } \\
\text { system needs an update. It is responsible for making decisions, obliging the offices with the } \\
\text { implementation, and also an exciting cooperation the departments." }\end{array}$ \\
\hline Monitoring and Evaluation & $\begin{array}{l}\text { Project Management } \\
\text { Abilities }\end{array}$ & $\begin{array}{l}\text { "Changing the current technology framework of the ministry, so the project management becomes } \\
\text { independent from the Change Management, it fully supervises the projects and their execution } \\
\text { process, and is connected to the general IT management." }\end{array}$ \\
\hline $\begin{array}{l}\text { Project Management \& } \\
\text { Governance }\end{array}$ & $\begin{array}{l}\text { Project Management } \\
\text { Abilities }\end{array}$ & $\begin{array}{l}\text { "The current project management receives applications to execute new projects and to put new } \\
\text { plans for that. I see it responsible for placing and implementing any new system in the ministry." }\end{array}$ \\
\hline Communication \& Cooperation & $\begin{array}{l}\text { Project Management } \\
\text { Abilities }\end{array}$ & $\begin{array}{l}\text { "This happens either because of poor understanding of dealing with the new operation, or poor } \\
\text { communication with other departments requesting the operation's execution." }\end{array}$ \\
\hline $\begin{array}{l}\text { Training \& Competence of } \\
\text { Stakeholders }\end{array}$ & $\begin{array}{l}\text { Project Management } \\
\text { Abilities }\end{array}$ & $\begin{array}{l}\text { "Continuously changing the human resources, and therefore, lack of maintenance of new specialist } \\
\text { skills for properly implementing this new technology. This is a challenge to the process of } \\
\text { continuous training of the employees on the way of implementing ITIL processes, and developing } \\
\text { them to assure a service quality for the client." } \\
\text { "Lack of employees' knowledge about ITIL operations because of no repetition of specialist } \\
\text { courses." }\end{array}$ \\
\hline $\begin{array}{l}\text { Change Management \& } \\
\text { Organisational Culture }\end{array}$ & $\begin{array}{l}\text { Project Management } \\
\text { Abilities }\end{array}$ & $\begin{array}{l}\text { "When a new project is required to be executed, if the change management believes it's not worth } \\
\text { execution, such a request would not be activated, and it would stop at this stage." }\end{array}$ \\
\hline Performance Expectancy & $\begin{array}{l}\text { Aligning with } \\
\text { Customer/EndUser }\end{array}$ & $\begin{array}{l}\text { "Help Service providers to focus their attention on the needs of the customers and user experience } \\
\text { rather than focussing too much on the technology issues. Also, ITIL provides processes and models } \\
\text { to help service providers to meet their business." }\end{array}$ \\
\hline Effort Expectancy & $\begin{array}{l}\text { Aligning with } \\
\text { Customer/EndUser }\end{array}$ & Not Addressed Directly \\
\hline Social Influence & Attitudinal & Not Addressed Directly \\
\hline Facilitating Conditions & Leadership & $\begin{array}{l}\text { "Training the employees was conducted by the upper management, and specialist consultants were } \\
\text { brought to provide courses on ITIL basics and the way to deal with new operations and } \\
\text { technological tools." }\end{array}$ \\
\hline Behavioural Intention & Attitudinal & $\begin{array}{l}\text { "There is a desire among the employees to learn ITIL technology, and to continue developing their } \\
\text { skills for a proper and faultless implementation." }\end{array}$ \\
\hline Attitude Toward Use & Attitudinal & $\begin{array}{l}\text { "Employee resistance to change, which requires that the employees need training on new } \\
\text { operations, and what benefits they would acquire after implementing ITIL for example." }\end{array}$ \\
\hline User Behaviour & Attitudinal & $\begin{array}{l}\text { "Among the problems we faced on, during ITIL implementation, was the culture of work on the new } \\
\text { operations whether that of the employees or the heads of departments in general." }\end{array}$ \\
\hline
\end{tabular}

In table 4 the respondents noted that there were some issues with the way that it was being implemented, in terms of there being issues with the old culture and way of doing things, a lack of knowledge and training about ITIL, and references to a high staff turnover and changes in human resources that made it difficult to maintain momentum. In this sense the research at present has captured an organisation in transition; it appears to have made substantial progress in implementing ITIL and delivering training, but is not yet gaining the full benefits of the program; a subsequent research project in a year or two years' time might reveal more quantifiable benefits and outcomes, with some of the cultural issues receding in importance $[2,15,42,43]$. 
TABLE IV. SUMMARY OF CONCEPTS INFLUENCE CSFS AdOPTION AT MOE IN SAUDI ARABIA

\begin{tabular}{|c|c|c|c|}
\hline Concept of CSFs & Themes & analysis & Interviewer's Notes \\
\hline $\begin{array}{l}\text { Training \& } \\
\text { Competence of } \\
\text { Stakeholders }\end{array}$ & $\begin{array}{l}\text { Project } \\
\text { Management } \\
\text { Abilities }\end{array}$ & $\begin{array}{l}\text { "Continuously changing the human resources, and } \\
\text { therefore, lack of maintenance of new specialist } \\
\text { skills for properly implementing this new } \\
\text { technology. This is a challenge to the process of } \\
\text { continuous training of the employees on the way of } \\
\text { implementing ITIL processes, and developing them } \\
\text { to assure a service quality for the client." } \\
\text { "Lack of employees' knowledge about ITIL } \\
\text { operations because of no repetition of specialist } \\
\text { courses." }\end{array}$ & $\begin{array}{l}\text { There was a clear focus on training as a } \\
\text { mechanism through which obstacles could be } \\
\text { removed, acceptance improved, and } \\
\text { performance improved. Again, this was linked } \\
\text { to the attitude of management, who both } \\
\text { conducted and commissioned training in order } \\
\text { to drive the process. }\end{array}$ \\
\hline $\begin{array}{l}\text { Facilitating } \\
\text { Conditions }\end{array}$ & Leadership & $\begin{array}{l}\text { "Training the employees was conducted by the } \\
\text { upper management, and specialist consultants were } \\
\text { brought to provide courses on ITIL basics and the } \\
\text { way to deal with new operations and technological } \\
\text { tools." }\end{array}$ & $\begin{array}{l}\text { Referenced directly in terms of the } \\
\text { management of the institution driving the } \\
\text { process, providing training and impetus to } \\
\text { maximize the chances of acceptance and the } \\
\text { efficacy of the ITIL implementation as a } \\
\text { whole. }\end{array}$ \\
\hline $\begin{array}{l}\text { Behavioural } \\
\text { Intention }\end{array}$ & Attitudinal & $\begin{array}{l}\text { "There is a desire among the employees to learn } \\
\text { ITIL technology, and to continue developing their } \\
\text { skills for a proper and faultless implementation." }\end{array}$ & $\begin{array}{l}\text { This was referenced by way of the fact that } \\
\text { there was generally a forward-looking } \\
\text { approach among the staff, and they were } \\
\text { willing to undergo training to help the process } \\
\text { along. }\end{array}$ \\
\hline $\begin{array}{l}\text { Attitude Toward } \\
\text { Use }\end{array}$ & Attitudinal & $\begin{array}{l}\text { "Employee resistance to change, which requires } \\
\text { that the employees need training on new } \\
\text { operations, and what benefits they would acquire } \\
\text { after implementing ITIL for example." }\end{array}$ & $\begin{array}{l}\text { The behavioural intention part was referenced } \\
\text { to the fact that some people were initially } \\
\text { resistant to change, as was the organizational } \\
\text { culture as a whole, but this was largely } \\
\text { ascribed to a natural part of organizational } \\
\text { culture and there was nothing particular to } \\
\text { ITIL that gave rise to this; and it was easily } \\
\text { dealt with through training and leadership. }\end{array}$ \\
\hline User Behaviour & Attitudinal & $\begin{array}{l}\text { "Among the problems we faced on, during ITIL } \\
\text { implementation, was the culture of work on the } \\
\text { new operations whether that of the employees or } \\
\text { the heads of departments in general." }\end{array}$ & As above \\
\hline
\end{tabular}

RQ2: What are some of the crucial factors for successful implementation of ITIL in the MoE in the KSA?

Of the factors in the conceptual model, there is merit to them all, but there is some difficulty in following that mapping in practice; the way that CSFs are named in each organisation is not necessarily that clear. Therefore, there is some initial value in reducing the number of CSFs in the overall conceptual model, since they cannot be distinguished effectively at that level, see table 5. Therefore, the model could be reduced to a series of factors that commence with strong leadership involvement as demonstrated by the current research, but then focus on simple three-stage set of CSFs: training, project management, and reflexivity $[34,36]$. Recasting the model in this form would allow the CSFs to be more clearly referenced against what is happening as the Ministry of Education seeks to implement ITIL as shows in table 5 .

This may seem to unnecessarily compress such proposed CSFs as communication abilities and the facilitation of the right conditions, but the data from these respondents would appear to show that it might not be preferable to have these as independent CSFs, but rather to suggest that in order for the CSFs of leadership, training, effective project management, and reflexivity, then these qualities need to be present, see table 5 [44-46]. Communication is not something that should be isolated into its own CSF, it is something necessary to ensure that all core CSFs are delivered effectively.

However, this would need to be set against the findings of the literature at large that would not recommend such a simplification process [47]. Other studies in organisations with less direct leadership styles than the Ministry of Education demonstrate that these factors relating to attitude and culture are important, particularly when it comes to matching the expectations of the user and delivering customer satisfaction, presented in table $5[36,48]$; therefore, this research project has probably demonstrated quite an abnormal case with a leadership style not possible to replicate in other organisations; therefore, simplifying the model based solely on this data would not be wise [49]. 
TABLE V. SOME OF THE CRUCIAL FACTORS FOR SUCCESSFUL IMPLEMENTATION OF ITIL IN THE MOE IN THE KSA

\begin{tabular}{|c|c|c|c|}
\hline Concept of CSFs & Themes & analysis & Interviewer's Notes \\
\hline $\begin{array}{l}\text { Top Management } \\
\text { Support }\end{array}$ & Leadership & $\begin{array}{l}\text { "The Manager of the Department of Application } \\
\text { Development is a specialist of ITIL, and he is the } \\
\text { one who supported the decision to apply ITIL, } \\
\text { together with a number of ITIL specialists." } \\
\text { "The upper management's support is the first factor } \\
\text { for a successful implementation of ITIL. This is } \\
\text { reflected in maintaining the current technology and } \\
\text { developing the operations whenever the system } \\
\text { needs an update. It is responsible for making } \\
\text { decisions, obliging the offices with the } \\
\text { implementation, and also an exciting cooperation the } \\
\text { departments." }\end{array}$ & $\begin{array}{l}\text { There was a very strong impression from the respondents } \\
\text { that ITIL was being driven hard in the organization, in that } \\
\text { management were very much behind it, and working hard to } \\
\text { both lead and create the right context for it to be rolled out. } \\
\text { Everything else has to be read through this lens; when they } \\
\text { were talking about the project management techniques etc, it } \\
\text { was in the context of a strong organizational desire to } \\
\text { implement ITIL. }\end{array}$ \\
\hline $\begin{array}{l}\text { Project } \\
\text { Management \& } \\
\text { Governance }\end{array}$ & $\begin{array}{l}\text { Project Management } \\
\text { Abilities }\end{array}$ & $\begin{array}{l}\text { "The current project management receives } \\
\text { applications to execute new projects and to put new } \\
\text { plans for that. I see it responsible for placing and } \\
\text { implementing any new system in the ministry." }\end{array}$ & $\begin{array}{l}\text { As above, this was a complex area - all the factors in the } \\
\text { conceptual model were present, but in a muddled form. } \\
\text { There was a notable degree of reflexivity, whereby there } \\
\text { could be feedback loops built into the process whereby work } \\
\text { could be continually amended dependent on quality control } \\
\text { and client feedback. }\end{array}$ \\
\hline $\begin{array}{l}\text { Communication } \\
\text { \& Cooperation }\end{array}$ & $\begin{array}{l}\text { Project Management } \\
\text { Abilities }\end{array}$ & $\begin{array}{l}\text { "This happens either because of poor understanding } \\
\text { of dealing with the new operation, or poor } \\
\text { communication with other departments requesting } \\
\text { the operation's execution." }\end{array}$ & $\begin{array}{l}\text { This was cited mainly in the context of potential } \\
\text { obstructions, but again, it has to be seen in the context of the } \\
\text { organizational will to implement ITIL; cooperation seemed } \\
\text { to be expected and demanded. }\end{array}$ \\
\hline $\begin{array}{l}\text { Performance } \\
\text { Expectancy }\end{array}$ & $\begin{array}{l}\text { Aligning with } \\
\text { Customer/EndUser }\end{array}$ & $\begin{array}{l}\text { "Help Service providers to focus their attention on } \\
\text { the needs of the customers and user experience } \\
\text { rather than focussing too much on the technology } \\
\text { issues. Also, ITIL provides processes and models to } \\
\text { help service providers to meet their business." }\end{array}$ & $\begin{array}{l}\text { This seemed to be implicit in much of what the responses } \\
\text { talked about; in that the discussions about some of the } \\
\text { project management and quality control tools were } \\
\text { predicated on the expectation that they would deliver a } \\
\text { better fit with the client expectations. }\end{array}$ \\
\hline Effort Expectancy & $\begin{array}{l}\text { Aligning with } \\
\text { Customer/EndUser }\end{array}$ & Not Addressed Directly & \\
\hline Social Influence & Attitudinal & Not Addressed Directly & \\
\hline $\begin{array}{l}\text { Facilitating } \\
\text { Conditions }\end{array}$ & Leadership & $\begin{array}{l}\text { "Training the employees was conducted by the } \\
\text { upper management, and specialist consultants were } \\
\text { brought to provide courses on ITIL basics and the } \\
\text { way to deal with new operations and technological } \\
\text { tools." }\end{array}$ & $\begin{array}{l}\text { Referenced directly in terms of the management of the } \\
\text { institution driving the process, providing training and } \\
\text { impetus to maximize the chances of acceptance and the } \\
\text { efficacy of the ITIL implementation as a whole. }\end{array}$ \\
\hline
\end{tabular}

\section{CONCLUSION}

The conceptual model in figure 3 was deployed into the research environment associated with the Ministry of Education in the KSA, through a series of interviews, in order to understand how ITIL was being used, the CSFs, and the outcomes of the process. The concept of the CSFs model in the current study were broadly borne out by the data, though it was found that the mechanics of project management and quality are more reflexive than the model describes, and the individual components of it become difficult to make clear. Therefore, on the basis solely of the evidence within this study, it might be appropriate to develop a simplified version of the model, but this would be over-fitted to the peculiar circumstances of the KSA and would not have any wider explanatory power beyond the specific context of this study. Therefore, it would be appropriate to conclude that the project has demonstrated that, in the unique context of the Ministry of Education in the KSA, certain aspects of the model like the concept of communication and cooperation support become more critical than others CSFs, probably due to the strong leadership shown in implementing ITIL, which in turn reduces or nullifies many of the attitudinal issues that are noted in other contexts. Even excluding this, the data demonstrate that the concept of CSFs in this study is the central important of reflexivity in the effectiveness of ITIL, which is perhaps the most important contribution of this research to the literature as a whole and achieved the objectives of this research.
Furthermore, this research has demonstrated that where there is very strong leadership, a lot of the CSFs such as communication and cooperation, and training and competence of stakeholders become less relevant because the attitudinal issues are smoothed away before they begin to disrupt the process. The overall of ITIL process is important because the evidence of this project, and a key conclusion, is that ITIL is working effectively in this context; the IT service delivery seems to have been improved both in terms of the service given to the end user, and the costs of delivering that service by the Ministry of Education in KSA.

\section{REFERENCES}

[1] L. Zhang and W. Wang, "Influential factors of employees' acceptance and use of ITSM in Chinese Banks based on empirical study," Advances in Information Sciences \& Service Sciences, vol. 4, 2012.

[2] J. Iden and L. Langeland, "Setting the stage for a successful ITIL adoption: A Delphi study of IT experts in the Norwegian armed forces," Information systems management, vol. 27, pp. 103-112, 2010.

[3] M. Farmand, "Proposing a comprehensive framework for ITSM efficiency," Master's thesis, University of Borås, Sweden, 2013.

[4] M. M. Mohammadi, A. Z. Ravasan, and H. Hamidi, "Investigating critical success factors in implementing ITIL framework: The case of a developing country," International Journal of Standardization Research (IJSR), vol. 13, pp. 74-91, 2015.

[5] C. Pollard and A. Cater-Steel, "Justifications, strategies, and critical success factors in successful ITIL implementations in US and Australian companies: an exploratory study," Information systems management, vol. 26, pp. 164-175, 2009. 
[6] B. McNaughton, P. Ray, and L. Lewis, "Designing an evaluation framework for IT service management," Information \& Management, vol. 47, pp. 219-225, 2010.

[7] M. Nicho and B. A. Mourad, "Success factors for integrated ITIL deployment: an IT governance classification," Journal of Information Technology Case and Application Research, vol. 14, pp. 25-54, 2012.

[8] M. B. Al Mourad and R. Johari, "Resolution of challenges that are facing organizations before ITIL implementation," International Journal of Future Computer and Communication, vol. 3, p. 210, 2014.

[9] J. Iden and T. R. Eikebrokk, "Implementing IT Service Management: A systematic literature review," International Journal of Information Management, vol. 33, pp. 512-523, 2013.

[10] W. J. Orlikowski and J. J. Baroudi, "Studying information technology in organizations: Research approaches and assumptions," Information systems research, vol. 2, pp. 1-28, 1991.

[11] A. Cater-Steel, M. Toleman, and W.-G. Tan, "Transforming IT service management-the ITIL impact," in Proceedings of the 17th Australasian Conference on Information Systems (ACIS 2006), Adelaide 2006.

[12] E. N. Nfuka and L. Rusu, "Critical success factors framework for implementing effective IT governance in public sector organizations in a developing country," in AMCIS, USA, 2011, p. 365.

[13] N. Ahmad and Z. M. Shamsudin, "Systematic approach to successful implementation of ITIL," Procedia Computer Science, vol. 17, pp. 237244, 2013.

[14] K. Pedersen, P. Kræmmergaard, B. C. Lynge, and C. D. Schou, "ITIL implementation: Critical success factors a comparative case study using the BPC framework," Journal of Information Technology Case and Application Research, vol. 12, pp. 11-35, 2010.

[15] M. Blumberg, A. Cater-Steel, and J. Soar, "An organisational change approach to implementing IT service management," in 25th Australasian Conference on Information Systems, ed. New Zealand: ACIS, 2014.

[16] A. Cater-Steel, W.-G. Tan, and M. Toleman, "Challenge of adopting multiple process improvement frameworks," in In 14th European Conference on Information Systems (ECIS), Sweden, 2006, pp. 13751386.

[17] H. Treiblmaier and P. Filzmoser, "Exploratory factor analysis revisited: How robust methods support the detection of hidden multivariate data structures in IS research," Information \& management, vol. 47, pp. 197207, 2010.

[18] Y. Al-Matari, A. Al-Swidi, and F. Fadzil, "Corporate governance and performance of Saudi Arabia listed companies," British Journal of Arts \& Social Sciences, vol. 9, pp. 1-30, 2012.

[19] P. Zahir Irani, N. Ahmad, N. Tarek Amer, F. Qutaifan, and A. Alhilali, "Technology adoption model and a road map to successful implementation of ITIL," Journal of Enterprise Information Management, vol. 26, pp. 553-576, 2013.

[20] V. Venkatesh, M. G. Morris, G. B. Davis, and F. D. Davis, "User acceptance of information technology: Toward a unified view," MIS quarterly, vol. 27, pp. 425-478, 2003.

[21] R. K. Yin, Case study research: Design and methods: Sage publications, 2013.

[22] H. K. Klein and M. D. Myers, "A set of principles for conducting and evaluating interpretive field studies in information systems," MIS quarterly, vol. 23, pp. 67-93, 1999.

[23] G. Walsham, "Interpretive case studies in IS research: nature and method," European Journal of information systems, vol. 4, pp. 74-81, 1995.

[24] N. King and C. Horrocks, Interviews in qualitative research. London: Sage, 2010.

[25] J. A. Maxwell, Qualitative research design: An interactive approach: An interactive approach, 3rd ed. USA: Sage, 2012.

[26] J. Corbin and A. Strauss, Basics of qualitative research: Techniques and procedures for developing grounded theory, 4th ed. Los Angeles: Sage publications, 2014.

[27] K. Charmaz, Constructing grounded theory: A practical guide through qualitative analysis (Introducing qualitative methods series). London: Sage Publications, 2006.
[28] J. Collis and R. Hussey, Business research: A practical guide for undergraduate and postgraduate students, 3rd ed. London, UK: Palgrave, 2009.

[29] L. Barriball and A. While, "Collecting Data using a semi-structured interview: a discussion paper," Journal of advanced nursing, vol. 19, pp. 328-335, 1994.

[30] E. Slevin and D. Sines, "Enhancing the truthfulness, consistency and transferability of a qualitative study: utilising a manifold of approaches," Nurse Researcher, vol. 7, p. 79, 1999.

[31] A. K. Shenton, "Strategies for ensuring trustworthiness in qualitative research projects," Education for information, vol. 22, pp. 63-75, 2004.

[32] M. Jäntti and V. Hotti, "Defining the relationships between IT service management and IT service governance," Information Technology and Management, pp. 1-10, 2015.

[33] K. Kanapathy and K. I. Khan, "Assessing the relationship between ITIL implementation progress and firm size: evidence from Malaysia," International Journal of Business and Management, vol. 7, pp. 194-210, 2012.

[34] J. Bröchner and U. Badenfelt, "Changes and change management in construction and IT projects," Automation in Construction, vol. 20, pp. 767-775, 2011.

[35] T. Diirr and G. Santos, "Improvement of IT service processes: a study of critical success factors," Journal of Software Engineering Research and Development, vol. 2, pp. 1-21, 2014.

[36] J. Iden and T. R. Eikebrokk, "Understanding the ITIL implementation project: conceptualization and measurements," presented at the 2011 22nd International Workshop on Database and Expert Systems Applications, IRIT, Paul Sabatier University,Toulouse, France, 2011.

[37] S.-J. Huang, M.-S. Wu, and L.-W. Chen, "Critical success factors in aligning IT and business objectives: A Delphi study," Total Quality Management \& Business Excellence, vol. 24, pp. 1219-1240, 2013.

[38] R. Esteves and P. Alves, "Implementation of an information technology infrastructure library process-the resistance to change," Procedia Technology, vol. 9, pp. 505-510, 2013.

[39] M. Gehrmann, "Combining ITIL, COBIT and ISO/IEC27002 for structuring comprehensive information technology for management in organizations," Navus: Revista de Gestão e Tecnologia, vol. 2, pp. 6677, 2012.

[40] M. B. Al Mourad and M. Hussain, "The impact of cloud computing on ITIL service strategy processes," International Journal of Computer and Communication Engineering, vol. 3, pp. 367-380, 2014.

[41] M. Kastelic and P. Peer, "Managing IT Services: Aligning Best Practice with a Quality Method," Organizacija, vol. 45, pp. 31-37, 2012.

[42] J. O. Long, ITIL Version 3 at a glance: information quick reference: Springer Science \& Business Media, 2008.

[43] M.-S. Wu, S.-J. Huang, and L.-W. Chen, "The preparedness of critical success factors of IT service management and its effect on performance," The Service Industries Journal, vol. 31, pp. 1219-1235, 2011.

[44] M. Lepmets, A. Cater-Steel, F. Gacenga, and E. Ras, "Extending the IT service quality measurement framework through a systematic literature review," Journal of Service Science Research, vol. 4, pp. 7-47, 2012.

[45] T. Lucio-Nieto, R. Colomo-Palacios, P. Soto-Acosta, S. Popa, and A. Amescua-Seco, "Implementing an IT service information management framework: The case of COTEMAR," International Journal of Information Management, vol. 32, pp. 589-594, 2012.

[46] J. Iden and T. R. Eikebrokk, "Using the ITIL process reference model for realizing IT Governance: An empirical investigation," Information Systems Management, vol. 31, pp. 37-58, 2014.

[47] M. Marrone, F. Gacenga, A. Cater-Steel, and L. Kolbe, "IT service management: a cross-national study of ITIL adoption," Communications of the association for information systems, vol. 34, pp. 865-892, 2014.

[48] P. Yamakawa, C. Obregón Noriega, A. Novoa Linares, and W. Vega Ramírez, "Improving ITIL compliance using change management practices: a finance sector case study," Business Process Management Journal, vol. 18, pp. 1020-1035, 2012.

[49] S. Taylor and I. Macfarlane, ITIL small-scale implementation: The Stationery Office, 2006. 